\title{
A LINGUÍSTICA E SUAS GENEALOGIAS: SOBRE PERCURSOS (DES)ENLAÇADOS
}

\section{LINGUISTICS AND ITS GENEALOGIES: ON INTERTWINED PATHWAYS}

\author{
Cristine Gorski Severo ${ }^{1}$ \\ Universidade Federal de Santa Catarina (UFSC) \\ Edair Maria Görski² \\ Universidade Federal de Santa Catarina (UFSC)
}

\section{RESUMO}

Este texto propõe-se a uma reflexão de caráter epistemológico em torno de discursividades historiográficas acerca da fundação da linguística, problematizando a ideia de uma narrativa fundante única, mediante uma retrospectiva orientada por uma visão estrutural, representada por Saussure e Camara Jr.; por uma visão focada na mudança linguística a partir de orientações estrutural e social, representada por Labov; e por uma perspectiva sociológica/filosófica de língua, representada por Voloshinov/Bakhtin - nomes de ampla circulação no meio linguístico brasileiro. Os recortes genealógicos resultantes permitem trazer à tona contribuições de autores muitas vezes invisibilizados, como William Jones e Jespersen, ou pouco reconhecidos, como Humboldt e Whitney. O texto relativiza discursos fundantes à luz de uma historicidade genealógica mais ampla, plural e comparada, constituída por séries muitas vezes interligadas. Nessa esteira, reflete-se também sobre a questão das paternidades da linguística.

PALAVRAS-CHAVE: séries genealógicas; paternidades; linguística.

\begin{abstract}
We propose to present and discuss the historical discourses related to the emergence of Linguistics, problematizing the idea of a unique founding narrative. The discussion is anchored in distinct perspectives about the emergence and consolidation of Linguistics, as the works of Saussure and Camara Jr. - representatives of a structural approach to language; of Labov, representing an approach to social change from both structural and social perspectives; and of Voloshinov/Bakhtin - representing a sociological/philosophical perspective. Such perspectives have a wide circulation in the Brazilian academic context. In addition to revealing elements that characterize the different approaches and also the elements that bring them closer together, we seek to bring contributions from authors who are often invisible, such as William Jones, Jespersen, Humboldt and Whitney. This article relativizes foundational discourses in the light of a more extensive, plural and compared genealogical historicity. In line with this, the question of paternity in Linguistics is also problematized.
\end{abstract}

KEYWORDS: genealogical series; paternities; linguistics.

\footnotetext{
1 Pós-doutora em Política Linguística pela Universidade Estadual da Pensylvannia. Doutora em Linguística e em Ciências Humanas pela Universidade Federal de Santa Catarina (UFSC). crisgorski@gmail.com.

2 Doutora em Linguística pela Universidade Federal do Rio de Janeiro (UFRJ). edagorski@hotmail.com.
} 


\section{INTRODUÇÃO}

Reconhecemos, com Benveniste (1989, p. 30), que "a lingüística teve vários começos. Ela recomeçou e se reengendrou a si mesma várias vezes - não sem se dar cada vez antecedentes”. Considerando que a maneira como os diferentes discursos que retratam o surgimento da linguística são construídos não é neutra, neste texto, de caráter expositivo e reflexivo, fazemos um recorte da historiografia a partir de diferentes perspectivas, colocando em tela e relativizando narrativas distintas que abordam a emergência e consolidação da linguística. As séries históricas reportadas são perpassadas pela explanação de alguns conceitos, nomes próprios e pequenos acontecimentos. Buscamos, desse modo, não só ilustrar a diversidade de enfoques e compreender a complexidade de certos embates em torno da língua - motivados por diferentes preocupações e indagações -, mas também situar alguns pontos de ruptura e aproximação entre as orientações aqui apresentadas. Reconhecemos que nosso recorte, bem como a escolha das fontes bibliográficas e das orientações genealógicas usadas, também não é neutro, sinalizando para gestos interpretativos nossos que buscamos evidenciar no decorrer do texto.

As séries genealógicas apresentadas atravessam os escritos de Saussure (1857-1913), Camara Jr. (1904-1970), Labov (1927-) e Voloshinov (1895-1936)/Bakhtin (1895-1975), ajudando a construir discursos fundantes da linguística. A escolha por esses nomes se justifica por serem reconhecidos como representativos de discursividades linguísticas que focalizam as dimensões estrutural e social da língua; e por serem de ampla circulação na linguística praticada no Brasil, especialmente na linguística descritiva (notadamente Saussure e Camara Jr.), na sociolinguística (Labov), na linguística aplicada e na análise do discurso (Voloshinov/Bakhtin). Na esteira das diferentes linhagens, também trazemos à tona paternidades atribuídas a alguns nomes próprios, especialmente Saussure, mostrando que essa pluralidade fundacional por vezes é apagada ou relativizada.

Cumpre salientar que não se trata, aqui, de propor uma historicidade para a linguística, conforme já amplamente debatida por diversos autores (ROBINS, 1967; WEEDWOOD, 2002; ALTMAN, 2004; ALLAN, 2013, entre outros). Nossa proposta é de tecer reflexões a partir de certas narrativas genealógicas que, muitas vezes, são tomadas isoladamente para legitimar um dado campo do saber. Não buscamos uma narrativa originária que defina a emergência da linguística, nem uma historiografia cronológica, linear e centrada nos grandes nomes. Nesse sentido, nos inspiramos nas reflexões foucaultianas para quem o trabalho historiográfico valoriza os desencontros, os acasos, os pequenos acontecimentos, aquilo que foi negligenciado ou subalternizado (FOUCAULT, 1979). Concordamos com Altaman (2004, p. 28), para quem um trabalho de historiografia em linguística "não pode se resumir a uma simples compilação de datas, fatos, títulos e nomes relacionados com os estudos das línguas e da linguagem". Neste texto, os nomes próprios são tomados como signos que definem orientações teórico-metodológica e um dado discurso passível de ser historicamente contextualizado e relativizado.

Embora a temática sobre uma historicidade plural da linguística não seja algo novo, acreditamos que uma revisitação de propostas genealógicas que ajudaram a constituir narrativas sobre a linguística tem relevância epistemológica, uma vez que, além de contribuir para evidenciar uma visão plural, coerente e dialógica como constitutiva da história da linguística, também possibilita ilustrar a maneira como diferentes autores validam e balizam suas concepções de língua a partir de determinadas narrativas historiográficas. Acreditamos, por fim, que a contribuição deste texto está também nos recortes genealógicos efetuados, que permitem: descortinar tanto elementos que os particularizam, quanto elementos que os aproximam; iluminar ideias de autores muitas vezes invisibilizados, como William Jones (1746-1794) e Jespersen (1860-1943), ou pouco reconhecidos, como Humboldt (1767-1835) e Whitney (1827-1894); colocar em relação autores que nem sempre 
são aproximados, como Labov e Voloshinov/Bakhtin; e problematizar a questão dos discursos fundantes, de forma a relativizá-los à luz de um olhar comparado.

O texto está organizado da seguinte maneira: na primeira seção, tratamos das genealogias presentes em Saussure e em Camara Jr., com foco na noção de forma e estrutura linguística; na segunda seção, discorremos sobre as linhagens delineadas por Labov, com atenção à mudança linguística a partir de perspectivas estrutural e social; na terceira seção, expomos as genealogias presentes na obra de Voloshinov/Bakhtin, orientadas por uma visão linguístico-filosófica sobre a natureza da linguagem; por fim, problematizamos a questão das paternidades atribuídas à linguística.

\section{Saussure e Camara Jr.: as genealogias e a dimensão estrutural}

No Curso de Linguística Geral - CLG (1916), texto atribuído a Saussure por seus discípulos, a história da linguística é apresentada a partir de uma sequência cronológica de três fases: a 'gramática' - representante da tradição lógica; a 'filologia' - com enfoque na interpretação de textos antigos; e a 'gramática comparada' ou 'filologia comparativa' - com interesse na comparação entre línguas. Em termos gerais, à gramática, caberia a construção de regras normativas derivadas de estudos gregos e latinos, sem uma preocupação científica. À filologia, competiria a fixação, interpretação e comentário de textos, com base em um método crítico. À gramática comparada, caberia a identificação de parentescos linguísticos.

De acordo com Saussure, os primeiros estudos comparativos (como os de Bopp e Schleicher, na primeira metade do século XIX), além de não terem nenhum caráter explicativo, não levavam em conta a dimensão histórica das línguas. A questão das condições de vida das línguas começou a ser discutida no último quartel do século XIX, com relevo para o trabalho de Whitney (1875) A vida da linguagem. A dimensão histórica teria sido incorporada, também nesse período, pelos neogramáticos (como Hermann Paul), que passaram a encadear historicamente os fatos linguísticos, transformando o conceito de língua como organismo vivo, vigente à época, na ideia de que as línguas são "produto do espírito coletivo dos grupos linguísticos” (SAUSSURE, 2004 [1916], p. 12). A gramática comparada e a perspectivação histórica de seus resultados estariam na base da 'linguística', cuja emergência seria marcada fortemente pela delimitação da natureza de seu objeto.

Segundo o $C L G$, caberiam à linguística as seguintes tarefas: descrever e historicizar todas as línguas no modelo de famílias linguísticas, reconstituindo suas línguas-mães; deduzir as leis gerais e universais subjacentes aos fenômenos linguísticos; e "delimitar-se e definir-se a si própria" (p. 13). No que tange especificamente às contribuições de Saussure à linguística geral, destacam-se: (i) a formalização e explicitação das dimensões sincrônica e diacrônica do estudo da linguagem como campos de investigação com métodos e princípios próprios; (ii) a distinção entre langue e parole, colocando em tensão os aspectos social e individual da linguagem; e (iii) a priorização da langue como sistema de elementos linguísticos inter-relacionados e passíveis de serem descritos (ROBINS, 1967). Vale notar, no entanto, que Benveniste atribui o apagamento da dimensão histórica dos estudos da linguagem/língua como elemento central no CLG: "Nenhuma parcela de história se mistura ao uso vivo da língua. Eis o que Saussure quis afirmar" (1974, p. 32).

O linguista brasileiro Mattoso Camara Jr., em sua obra História da Linguística (1975), propõe uma visão evolutiva, indicando a existência de três fases que, porventura, poderiam se sobrepor: 'prélinguística', 'paralinguística' e 'linguística', sendo que esta última teria surgido no final do século XVIII. Os estudos pré-linguísticos estariam fundamentados no princípio de certo-errado, já existente no período antigo ocidental e indiano; e os paralinguísticos incluiriam as reflexões sobre a língua a partir de um viés filosófico, cujos expoentes foram Platão e Aristóteles. Entre essas duas fases estaria a tradição filológica, que intercalou a orientação (normativa) da gramática com reflexões filosóficas e 
existiu nos contextos indiano, grego e romano, perpassando os tempos. No período moderno, os estudos paralinguísticos incluíram nomes como Leibniz, Herder, Hobbes e Rousseau. Um dos nomes, contudo, cujos trabalhos são avaliados por Camara Jr. como "mais do que um mero estudo "paralinguístico" (1975, p. 37), é o de Humboldt (1767-1835), que teria, junto com os comparativistas, como Rask (1787-1832), semeado os fundamentos dos estudos linguísticos. Note-se que o papel dos estudos históricos na emergência da linguística também é apontado por Camara Jr. (1975, p. 35): "[...] uma nova abordagem à linguagem pouco a pouco tomava corpo: o estudo 'histórico' da linguagem, pelo qual o homem chegaria à lingüística propriamente dita”.

Já no texto "O Estruturalismo", publicado na revista Alfa em 1967, Camara Jr., assumindo o estruturalismo linguístico como eixo condutor de suas reflexões, propõe quatro séries históricas de estudo da língua. Tais séries incluem: (i) os analogistas - que compreendem filósofos e estudiosos da língua, desde a Antiguidade, os quais, embora prescindindo de um conceito de estrutura, tomaram o princípio de regularidade formal como base de funcionamento empírico da língua e como condição para sua sistematização; são representados, de forma geral, pela escola de Alexandria, culminado na concepção de gramática psicológica de Hermann Paul, no final do século XIX; (ii) os anomalistas cuja perspectiva, defendida pelos estóicos, considera os fatos da língua isoladamente, baseando-se pelo princípio da irregularidade e da singularidade do fenômeno linguístico, o que seria, para Camara Jr., um "anti-estruturalismo", similar ao estudo de atos de fala que desconsidere a gramática; representantes modernos dessa visão incluiriam Schuchardt, Gilliéron e a estética de Croce e Vossler, também no final do século XIX; (iii) a tradição lógico-gramatical - de base idealista e mais próxima dos analogistas, sendo representada por Aristóteles, Platão, Dionísio de Trácia e os gramáticos de Port-Royal; e (iv) a relação entre linguística e biologia - tomando a língua como organismo vivo, conforme as reflexões de Schleicher, em meados do século XIX.

As bases da concepção estrutural de língua, para o linguista brasileiro, não estariam, contudo, em nenhuma das quatro séries elencadas acima, mas "alhures [...] na teoria da forma lingüística que Humboldt desenvolveu" (1967, p. 45), tomada como uma construção ideal, um conceito. Nos termos de Camara Jr., caberia, por fim, a Saussure constituir "a primeira posição, rigorosa e conscientemente estruturalista" (p. 49). O linguista brasileiro ressalta, porém, que a concepção de língua de Saussure como instituição social não seria uma inovação, mas herdeira das ideias de Whitney e da sociologia francesa de Durkheim.

Como vimos, as propostas genealógicas de Saussure (CLG) e de Camara Jr. acerca do surgimento da linguística como um campo moderno de estudo da linguagem se assentam em critérios bastante aproximados, pautados por uma certa linearidade, embora um tanto distintos. Saussure parte de (i) uma diferenciação teórico-metodológica e hierarquização da linguística em relação a outros saberes, como a gramática, a filologia e os estudos comparados, para chegar à (ii) definição e delimitação da língua como objeto da linguística, e à (iii) delimitação desse objeto a partir de uma dinâmica interna e sistêmica ou estrutural. Camara Jr. evoca categorias classificatórias que agrupam concepções em torno do que seria "mais ou menos linguístico" (pré-linguística, paralinguística e linguística), ou ainda do que seria um pré- e um anti-estruturalismo (analogistas e anomalistas), para culminar no estruturalismo saussuriano. $\mathrm{O}$ que ambas as genealogias evidenciam claramente são caminhos que levam à dimensão estrutural da língua. Além disso, cabe notar o lugar de Whitney, sinalizado por Saussure e por Camara Jr., e o de Humboldt, acentuado por Camara Jr., na história dos estudos linguísticos e na emergência do estruturalismo moderno.

Saussure e Camara Jr. são, indubitavelmente, tidos como fundadores/precursores do(s) estruturalismo(s) linguístico(s) (em geral e no Brasil, respectivamente). Essa orientação teórica, contudo, também se tornou alvo de contestação e problematização, ajudando a reforçar e rememorar 
outras genealogias possíveis para o surgimento e consolidação da linguística, conforme veremos nas duas seções seguintes.

\section{Labov e as séries históricas}

Voltamo-nos a seguir, para as linhagens delineadas por Labov. A escolha por esse autor se justifica pelo diálogo que estabelece com o estruturalismo saussuriano e, como já afirmado, pela ampla circulação de suas ideias no cenário linguístico brasileiro, notadamente na área da sociolinguística.

Tendo como eixo motivador a mudança linguística, Labov (2008 [1972]) separa os estudiosos que abordaram esse tema, a partir do final do século XIX, em dois amplos grupos, considerando a concepção de língua de cada autor, bem como o foco de interesse: (i) na comunicação da informação referencial/representativa, de expressão de ideias, tratando do indivíduo - o 'grupo associal'; ou (ii) nos usos expressivos e diretivos da língua, tratando de questões sociais - o 'grupo social'. $\mathrm{Na}$ caracterização do autor, o primeiro grupo considera fatores puramente internos (estruturais ou psicológicos), assume uma comunidade homogênea e monolíngue e trabalha com o modelo de árvore genealógica para explicar a evolução linguística. Já o segundo contempla fatores sociais, enfatiza a diversidade e o contato linguístico, vendo a mudança em andamento refletida em mapas dialetais, e toma o modelo de ondas para explicar a evolução linguística.

No grupo associal, Labov alinha os seguintes autores: Paul, Sweet, Bloomfield, Kurylowikz, Trubetzkoy, Martinet, Chomsky e Halle. Saussure, pelo seu enfoque imanentista da língua, é vinculado a esse grupo, mas ganha pouco destaque na linhagem uma vez que postula uma abordagem sincrônica da língua, associando a mudança à diacronia ${ }^{3}$. Já o grupo social é formado pelos seguintes nomes, conforme uma certa cronologia: Whitney, Schuchardt, Meillet, Vendryes, Jespersen e Sturtevant. A partir de um olhar mais atento para as ideias de cada um desses autores do grupo social, sugerimos que eles sejam distribuídos ainda em dois subgrupos: de um lado, os quatro primeiros convergem no que diz respeito ao caráter social da linguagem tomado em sentido amplo; de outro lado, os dois últimos se aproximam por um olhar social mais localizado. O fato de Labov não ter proposto essa ramificação do grupo social suscita alguns questionamentos: fatores concernentes à situação interativa que envolve a relação eu-tu seriam, para o autor, da mesma dimensão que fatores sociais mais amplos como nível socioeconômico, idade e sexo dos falantes? Fatores contextuais que circundam o ato de fala seriam da mesma natureza que fatores contextuais que identificam grupos sociais, comunidades de fala, uma dada sociedade de determinada época? Não obstante a relevância de tais perguntas, discutir essas questões associadas à perspectiva laboviana escapa ao propósito deste artigo.

Ainda sobre o grupo social e suas ramificações, no primeiro subgrupo social, Whitney, concebendo a fala como posse social e não individual, defendia a ideia de língua como instituição social e acreditava que circunstâncias externas eram responsáveis pela mudança linguística. Schuchardt, por sua vez, interessava-se pelas variedades de fala e pelas condições sociais do surgimento e desenvolvimento de línguas em situação de contato, chamando a atenção para o papel condicionante do contexto social e cultural da língua nos processos de variação e mudança ${ }^{4}$; não

\footnotetext{
3 Considerando que as ideias imanentistas do grupo associal já foram contempladas na seção precedente, damos prioridade ao grupo social nesta seção.

4 Schuchardt se destacou por sua concepção de 'mistura' em linguagem: "há mistura de formas de um falante para outro dentro da mesma língua, mistura de maneiras de falar local e mesmo mistura de línguas diferentes" (CAMARA Jr., 1975, p. 101-102).
}

Revista do GELNE, Natal/RN, Vol. 21 - Número 1: p. 178-190. 2019 
obstante, defendia que a mudança linguística fosse vista em relação com o pensamento individual do falante, seguindo uma concepção subjetivista da língua. Já Meillet, que, na trilha de Whitney, concebia a língua como fato social, sob influência do sociólogo Durkheim, tinha uma concepção sociológica do falante, acreditando que as condições sociais seriam determinantes da variação e da mudança linguística. Nessa mesma direção segue Vendryes, ao defender que a linguagem resulta do grupo social.

No segundo subgrupo, Jespersen e Sturtevant enfatizam o papel da língua na interação social. Nos termos de Labov (2008 [1972], p. 304), "encontramos ao longo de toda a sua obra [de Jespersen] uma preocupação com as funções expressivas e diretivas da língua que entra fortemente em suas discussões sobre a mudança linguística". Para Jespersen (1922, p. 7-8), "a linguagem é atividade, atividade com propósito [...] e nunca deveríamos perder de vista os indivíduos falantes e seus propósitos de agirem dessa maneira em particular" 5 . Em relação a Sturtevant, Labov salienta o papel dos valores sociais e afetivos, notadamente associados à noção de prestígio, que ganhava destaque nos mecanismos de mudança propostos por aquele autor. Considerando que a principal função da linguagem é social - possibilitar a cooperação e interação entre os membros de um grupo -, Sturtevant (1947, p. 3) destaca: "uma língua não pode funcionar normalmente a menos que haja pelo menos dois falantes. Quando apenas um falante se mantém, a língua pode ser considerada como morta." ${ }^{\prime}$ Note-se que o componente social adquire, em Jespersen e Sturtevant, um caráter mais específico, associado tanto a aspectos que envolvem diretamente o falante e o ouvinte, como a aspectos decorrentes de avaliação social das formas linguísticas. Não por acaso, Labov evoca as funções expressivas e diretivas da linguagem - seguindo a proposta bühleriana -, ao se referir a Jespersen, colocando em evidência os participantes da situação comunicativa. Enquanto a função representativa, ou referencial, da linguagem diz respeito ao mundo, ou ao domínio do indivíduo/objeto (terceira pessoa), a função expressiva, ou emotiva, está centrada no falante e a diretiva, ou conativa, no ouvinte.

O exposto nos parágrafos precedentes suscita algumas reflexões. Como já referido, as linhagens apresentadas por Labov são organizadas em função de como a mudança linguística era concebida a partir do final do século XIX, e o critério que contrasta grupo associal versus grupo social situa, cronologicamente, no primeiro grupo o neogramático Paul e no segundo Whitney, como os respectivos pontos de partida de cada série. Note-se, contudo, que o marco inicial do surgimento da linguística tem sido associado a diferentes nomes a depender da perspectiva assumida pelo historiador e do recorte que ele propõe. Retrocedendo cerca de um século em relação ao recuo feito por Labov e tomando como foco a linguística histórica, Faraco (2005), por exemplo, considera dois grandes períodos cronológicos: o primeiro (1786-1878), da formação e consolidação do método comparativo, a partir de estudos do sânscrito, cujo ponto de origem foi William Jones (1746-1794); e o segundo (de 1878 até os dias de hoje), dos estudos neogramáticos e da linguística moderna, iniciado por Paul, entre outros pensadores alemães. Atente-se, pois, para o fato de que tanto o ponto de partida de cada série genealógica como a direção seguida e os nomes que as constituem são sempre determinados pela lente do historiador.

Carregando marcas dessas trajetórias, a linguística moderna evidencia uma tensão contínua entre duas linhas interpretativas, que por vezes se interpenetram: uma mais imanentista, que vê a mudança como um acontecimento condicionado por fatores internos, da própria língua, linha que

\footnotetext{
5 "[l]anguage is activity, purposeful activity [...] and we should never lose sight of the speaking individuals and of their purpose in acting in this particular way". As traduções ao longo do texto são de nossa responsabilidade.

6 "a language cannot function normally unless there are at least two speakers of it. When only one speaker remains, the language may be said to be dead."
}

Revista do GELNE, Natal/RN, Vol. 21 - Número 1: p. 178-190. 2019 
orienta os movimentos: neogramáticos $>$ estruturalismo > gerativismo; e outra mais integrativa, que entende a mudança como articulada com o contexto social que circunda os falantes, vendo a mudança condicionada tanto por fatores internos de natureza estrutural, como externos, de natureza social, linha que ancora: crítica aos neogramáticos $>$ dialetologia $>$ sociolinguística (FARACO, 2005). As duas linhagens sugeridas por Labov se situam no período que se inicia com os neogramáticos, correlacionando-se, grosso modo, com a tensão apontada por Faraco entre uma visão imanentista e outra integralista, podendo-se estabelecer uma aproximação entre grupo associal e visão imanentista, e grupo social e visão integralista. Observe-se que embora Labov, em seus trabalhos, se identifique com o grupo social, ao conceber a língua como socialmente motivada, ele também se interessa por fatores estruturais internos à língua, priorizando a função representativa da linguagem, o que o aproxima também do grupo associal.

A seguir expomos as visões genealógicas apresentadas por Voloshinov/Bakhtin, apontando a defesa que fazem de uma perspectiva sociológica da linguagem.

\section{Voloshinov/Bakhtin e as séries históricas}

No contexto russo, em Marxismo e Filosofia da Linguagem (MFL, 1988 [1929]), Voloshinov/Bakhtin, ao tomar como ponto de partida as reflexões sobre a natureza da linguagem, apresentam duas orientações genealógicas para contextualizar o "pensamento filosófico-linguístico" moderno (p. 69): o 'subjetivismo idealista' e o 'objetivismo abstrato'. Ressalte-se que o caráter genérico de tais termos é problematizado pelos próprios autores por não recobrirem a complexidade de cada orientação. Os autores afirmam, ainda, que o surgimento da linguística se filia aos estudos filológicos indo-europeus voltados para as "línguas mortas" (p. 97), sendo que os sacerdotes teriam sido os primeiros filólogos a decifrar os textos sagrados em línguas estrangeiras. Aliás, Voloshinov/ Bakhtin (1988 [1929]) consideram que desde a antiguidade a questão linguística fundamenta-se na compreensão da palavra estrangeira. Antes de esmiuçar as duas orientações, subjetivista e objetivista, apresentamos, sucintamente, as condições epistemológicas e políticas subjacentes à produção de MFL, pois compreendemos que o contexto vivenciado pelos autores influenciou fortemente suas ideias.

Tratou-se de um período marcado pelas revoluções de 1917, pela recepção da obra de Saussure na Rússia e pela herança epistemológica da linguística histórico-comparativa do século XIX (ALPATOV, 2011). As orientações teórico-metodológicas e políticas existentes no pensamento russo variavam de acordo com duas escolas de linguística (BRANDIST, 2006): (i) o Círculo de Moscou (1915) - que se caracterizou por uma rejeição à tradição psicológica em prol dos estudos formalistas e dialetológicos, cujo potencial sociológico teria se desenvolvido apenas a partir de 1917; e pela presença de alguns intelectuais, como Peterson e Vinokur, que foram, nos anos 1920, influenciados pelas reflexões de Meillet e Vandryes acerca da dimensão social da linguagem; e (ii) a Escola linguística de Leningrado - que recebeu uma forte influência de Baudouin de Courtenay e uma menor influência das ideias de Saussure, embora tenha sido afetada pelas ideias psicológicas e pelo estudo funcional das línguas; essa escola foi frequentada, entre outros, por Iakubinskii, aluno de Courtenay, que desenvolveu reflexões sobre as funções dialógicas e monológicas da linguagem (e as funções interpessoal e ideológica), além de se voltar para uma análise marxista da linguagem e para questões de políticas linguísticas. Essa discussão inspirada em Iakubinskii foi levada adiante por Voloshinov e Bakhtin, que propuseram, junto com outros intelectuais, uma visão sociológica, de inspiração marxista.

Retomando as duas orientações abordadas por Voloshinov/Bakhtin, os elementos que caracterizam a orientação subjetivista são: foco no ato de fala individual, criativo e ininterrupto, cujas 
leis de funcionamento são dadas pela psicologia individual; submissão da língua ao domínio estético e estilístico; negação do positivismo linguístico e de seu enfoque nas formas linguísticas e no ato psicofsiológico. Os representantes dessa orientação seriam: Herder, Humboldt, Vossler, Potebniá, Spitzer, Croce, entre outros filiados ao Romantismo, cada qual com suas especificidades. Embora os autores inscrevam Humboldt nessa orientação filosófico-linguístico, eles reconhecem a singularidade e complexidade de seu pensamento, o que teria feito com que "Humboldt [pudesse] tornar-se o iniciador de diferentes correntes profundamente divergentes entre si" (VOLOSHINOV/ BAKHTIN, 1988 [1929], p. 73).

A segunda orientação linguístico-filosófica é o objetivismo abstrato, cujas bases teóricometodológicas incluem: o sistema linguístico tomado como eixo organizador dos fenômenos linguísticos e cujas leis de funcionamento são imanentes; o foco conferido ao produto linguístico estável e sincronicamente localizado, bem como aos elementos linguísticos reiteráveis, frutos da convenção; a independência atribuída ao sistema em relação aos atos de fala individuais; a articulação da visão linguística com um modelo matemático e lógico. Os representantes dessa orientação teriam sua origem no racionalismo dos séculos XVII e XVIII, com Descartes e Leibniz, culminando com as ideias dos neogramáticos, de Durkheim, Meillet, Saussure, Bally e Sechehaye: "Saussure deu a todas as ideias da segunda orientação uma clareza e uma precisão admiráveis" (VOLOSHINOV/ BAKHTIN, 1988 [1929], p. 84). Os autores russos afirmam, ainda, que as influências de Saussure no contexto russo foram mais extensas do que as da tradição subjetivista de Vossler.

Nota-se que as séries perfiladas por Voloshinov/Bakhtin são fortemente afetadas pelas circunstâncias e pensamento da época, salientando-se o contraste representativo entre Humboldt (inscrito na orientação subjetivista) e Saussure (na orientação objetivista), bem como o forte papel do segundo no contexto linguístico russo. Diferentemente dessas duas orientações, Bakhtin/Voloshinov (1988 [1929]), aproximando-se de uma abordagem de viés marxista, assumem uma perspectiva social e sociológica da linguagem, em que as dimensões ideológica e linguística se articulam mutuamente, sendo que as enunciações constituem atos de linguagem inscritos em uma teia comunicativa dialógica e social que envolve a interação entre locutor e ouvinte e cujos sentidos são definidos contextualmente.

Vimos, na segunda e na terceira seção, que tanto Labov como Voloshinov/Bakhtin se voltam para a dimensão social da língua, interesse que os aproxima em contraste com a visão imanentista da língua postulada por Saussure, e que os situa como representantes proeminentes da sociolinguística americana e da sociolinguística russa, respectivamente. As séries genealógicas delineadas por esses autores, de alguma maneira, criam condições para que as suas concepções de língua sejam desenvolvidas. Diferentemente de Labov, que se situa no entremeio do estrutural e do social, com sua abordagem da língua como sistema heterogêneo socialmente motivado, Voloshinov/Bakhtin propõem uma abordagem que se distancia do subjetivismo idealista e do objetivismo abstrato, alinhando-se a uma visão sociológica da língua com forte viés ideológico.?

\section{A linguística e a questão das paternidades}

Nas seções anteriores, percebemos que as séries genealógicas apresentadas sinalizam, de alguma maneira, para o papel e importância de Saussure na constituição da linguística, a exemplo de Camara Jr., Labov e Voloshinov/Bakhtin, que aproximam Saussure de uma perspectiva estrutural. Tendo em mente que Saussure tem sido considerado de forma ampla e recorrente o "pai da

\footnotetext{
7 Para uma discussão detalhada sobre a relação entre os pensamentos de Labov e de Voloshinov/Bakhtin, conferir Severo (2007; 2009) e Bragança (2017).
}

Revista do GELNE, Natal/RN, Vol. 21 - Número 1: p. 178-190. 2019 
linguística moderna", dedicamos esta seção a uma reflexão acerca da questão da paternidade da linguística, assumindo seu caráter plural.

Não pretendemos aqui ratificar o lugar epistemológico e político fundante ${ }^{8}$ atribuído a Saussure e, tampouco, desvalorizá-lo; trata-se, tão somente, de problematizá-lo à luz de outras narrativas possíveis de serem contadas sobre o surgimento da linguística, incluindo a narrativa existente no próprio Curso de Linguística Geral, por entendermos que o status de paternidade foi atribuído a Saussure a posteriori. A título de exemplificação, Benveniste (1989, p. 31) assim define o papel desempenhado pelo linguista suíço: "Saussure, ele não é um começo, ele é outra coisa, ou é um outro tipo de começo. Sua contribuição consiste nisto: 'a linguagem, diz ele, é forma, não substância"”.

Por outro lado, o próprio Saussure, em suas "Notas para um artigo sobre Whitney", publicadas nos Escritos de Linguística Geral (2002, p. 181), afirma que a definição de Whitney de linguagem como instituição humana "mudou o eixo da lingüística". Sua contribuição, segundo Saussure, extrapola os estudos comparados, tendo deixado como legado "uma visão superior e geral sobre a linguagem: sendo essa, justamente, sua originalidade [...] o que Whitney, em 1867, foi o primeiro a dizer, não foi ainda tomado de nulidade em 1894, conforme o testemunho universal" (p. 183-191) $)^{9}$.

Nesse âmbito das paternidades e nomes fundadores, Robins (1967, p. 200) reconhece uma relação entre o pensamento saussuriano e as ideias do linguista prussiano Humboldt: "a extensão com que Saussure teria sido diretamente influenciado por Humboldt é incerta, embora uma conexão tenha sido sugerida"10; ademais, Robins (1967, p. 174) identifica Humboldt, ao lado de Saussure, como um dos possíveis fundadores da linguística moderna ${ }^{11}$ :

Wilhelm von Humboldt foi um dos pensadores mais profundos sobre as questões de linguística geral no século dezenove, e é possível indagar se seu estilo tivesse sido menos difuso e suas ideias mais bem trabalhadas e exemplificadas, e se suas obras volumosas tivessem sido mais amplamente conhecidas, ele não receberia uma posição comparável a de Saussure, como um dos fundadores do pensamento linguístico moderno. ${ }^{12}$

Ainda sobre o caráter inovador das ideias de Humboldt, Camara Jr. (1975, p. 37) afirma: "Podemos dizer que ele começou a lançar os fundamentos do que vimos chamando o estudo 'descritivo' da linguagem como um aspecto da lingüística propriamente dita. [...] Prefere, a isso, uma série de raciocínios acerca da linguagem em geral, alicerçando-os com exemplos das mais variadas

\footnotetext{
${ }^{8} \mathrm{Na}$ Seção 1, já enfatizamos algumas das principais contribuições de Saussure que, entre outras, justificariam o título de "pai da linguística moderna", que lhe tem sido atribuído.

9 A originalidade das ideias de Whitney também é sinalizada por Cruz, autor do prefácio e tradutor para o português da obra A vida da linguagem de Whitney. Nas palavras do tradutor (2010, p. 07): “[...] esse clássico de William Dwight Whitney, publicado em 1875, estabelece as bases da linguística moderna, fixando, por assim dizer, a agenda de muitos dos estudos linguísticos que se desenvolverão ao longo de todo o século XIX”. Curioso notar que essa mesma avaliação inovadora e fundadora não é ratificada pelo historiador da linguistica Robins, que tende a reconhecer com maior distinção o papel desempenhado por Humboldt na configuração da linguística moderna.

10 "the extend to which de Saussure was directly influenced by Humboldt is uncertain, though a connection has been suggested".

${ }^{11}$ Esse lugar de fundador atribuído a Humboldt também é reforçado por Heidermann, organizador e um dos tradutores para língua portuguesa da obra Humboldt - linguagem, literatura e bildung (2006).

12 "Wilhelm von Humboldt was one of the profoundest thinkers on general linguistic questions in the nineteen century, and one wonders whether, if his style had been less diffuse and his ideas more worked out and exemplified than they were, and his voluminous works were better known and more widely, he would not be accorded a position comparable to that given to Saussure as one of the founders of modern linguistic thought."
} 
línguas”. Um nome pouco reconhecido pela historiografia da linguística que também salientou o papel emblemático desempenhado por Humboldt na constituição das ideias linguísticas foi o dinamarquês Otto Jespersen, que considera o linguista alemão como um dos mais profundos pensadores da linguística, alguém que "enquanto desempenhava um papel importante no mundo político, encontrou tempo para estudar uma grande diversidade de línguas e pensar profundamente sobre muitos problemas vinculados à filologia e à etnografia."13 (JESPERSEN, 1922, p. 56).

Além de Whitney e Humboldt, e principalmente de Saussure, um outro nome emblemático nos discursos fundantes da linguística é o do jurista inglês William Jones, que realizou uma análise comparada sobre o sânscrito, o grego e o latim e as línguas germânicas (CAMARA Jr., 1974). Ressalte-se que o século XVIII foi uma fase de estudos epistemológicos e descritivos embalados pela "descoberta" feita pelos europeus de um modelo gramatical e fonético altamente elaborado presente na gramática do sânscrito redigida por Pãnini (520 a.C.-416 a.C.): "O impacto do trabalho de Pãnini e de outros linguistas indianos nos estudos do sânscrito na Europa a partir de 1800 foi profundo e de grande alcance." ${ }^{\prime 14}$ (ROBINS, 1967, p. 148). Nesse sentido, segundo Faraco (2004, p. 31), inspirado em Robins (1967), o nascimento da linguística teria ocorrido no século XVIII, tendo como mote o estudo intenso e comparado do sânscrito: "Toma-se como primeira data referencial deste período, o ano de 1786, em que William Jones apresentou sua comunicação à Sociedade Asiática de Benguela." Similarmente, nas palavras de Robins (1967, p. 134),

Se um único ano, embora artificialmente, pudesse ser considerado como marco do início da fase contemporânea da ciência linguística, seria 1786 [...] neste ano, como agora sabemos, Sir William Jones da Companhia da Índia Oriental leu seu famoso artigo para a Sociedade Asiática Real em Calcutá. ${ }^{15}$

Há, inclusive, quem atribua a Pãnini o papel de iniciador da linguística, como Benveniste (1974, p. 30): "Hoje, descobre-se um outro começo, fora e bem longe do mundo clássico, é a teoria indiana de Pãnini. Temos aí algo de extraordinário, uma descrição lingüística puramente formal que data, segundo estimativa mais prudente, do século IV antes de nossa era.".

O lugar de paternidade da linguística comparada e indo-europeia conferido a William Jones é, ainda, relativizado por Campbell (2006), que elenca uma série de estudiosos que já teriam, antes de Jones, proposto análises comparadas do sânscrito com línguas europeias. Ademais, o mesmo autor afirma que o interesse de Jones não se restringia às línguas, mas estava a reboque de um projeto mais ambicioso: redigir, em onze ensaios publicados na revista da Sociedade Asiática, a história da humanidade na Ásia. Campbell (2006) sinaliza que: (i) esse amplo interesse de Jones pela história da humanidade - em que a língua foi tomada como um dos elementos dessa história - embalou o espírito acadêmico dos séculos XVIII e XIX, a exemplo também dos trabalhos de Humboldt; (ii) a análise genealógica de distribuição de línguas e grupos étnicos proposta por Jones esteve a reboque de uma interpretação bíblica de origem do mundo a partir da descendência de Noé - a tese da tábua das Nações.

\footnotetext{
13 "while playing an important part in the political world, found time to study a great many languages and to think deeply on many problems connected with philology and ethnography."

14 "The impact of the work of Pãnini and other Indian linguists on Sansckrit studies in Europe from 1800 was deep and far reaching."

15 "[i]f any single year can, albeit artificially, be taken to mark the start of the contemporary world of linguistic science, it is the year 1786 [...] in this year, as we now know, Sir William Jones of the East India Company read his famous paper to the Royal Asiatic Society in Calcutta [...]."
}

Revista do GELNE, Natal/RN, Vol. 21 - Número 1: p. 178-190. 2019 
Além desses "pais" tomados como nomes fundadores e precursores da linguística, é possível demarcar alguns fatos políticos que ajudaram a inscrevê-la na ordem da sua institucionalização e legitimação. É o caso, por exemplo, do surgimento da disciplina acadêmica de Filologia Comparada e Histórica nas universidades europeias, especialmente na Alemanha, no início do século XIX, bem como da emergência do rótulo de "linguista" inicialmente atribuído, por exemplo, a Bacon (15611626), a Locke (1632-1704), a Leibniz (1646-1716) e a Condillac (1715-1780) (DAVIES; LEPSCHY, 1998). Ademais, o processo de institucionalização da linguística foi perpassado pela produção de publicações e eventos especializados sobre o tema, tendo sido os periódicos dedicados aos estudos orientais e asiáticos os primeiros a surgir, no início do século XIX, como o Journal Asiatique (PARIS, 1822-) e o Journal of the Royal Asiatic Society (LONDRES, 1823-); também podemos mencionar a criação das sociedades e associações de linguística, como a Société de Linguistique de Paris, em 1866 (DAVIES; LEPSCHY, 1998). No Brasil, a primeira geração de acadêmicos, dos anos 1930, e a segunda geração, dos anos 1950, se filiaram à tradição germânica de estudos da linguagem. Já os anos 1970 marcaram o surgimento dos primeiros linguistas brasileiros, a exemplo de Camara Jr., sendo que a disciplina de Linguística foi institucionaliza apenas em 1962; ademais, este autor é considerado um dos precursores da linguística no Brasil, conforme atestado por Altman (2012, p. 24): "Acredito que a unanimidade dos linguistas brasileiros contemporâneos não hesitaria em reconhecer que é Mattoso Câmara quem deva ocupar o honroso lugar de precursor da ciência linguística no país [...]”.

Percebemos que a questão da paternidade se vincula aos discursos genealógicos de diferentes maneiras: se Saussure é considerado o pai da linguística moderna, William Jones, por sua vez, é tido como o pai da linguística comparada. Pãnine, nessa ótica, poderia ser colocado como o pai da linguística descritiva; Whitney seria o pai de uma linguística de orientação social; e Humboldt assumiria um lugar de paternidade mais amplo, a partir de quem diferentes orientações teóricas teriam se desenvolvido. Por outro lado, podemos desdobrar o tema da paternidade entre precursores, fundadores, consolidadores e desenvolvedores, conforme proposto por Davies e Lepschy (1998). Para esses autores, a classificação dos nomes na historiografia linguística seria a seguinte: haveria (i) os precursores e fundadores, entre os quais estariam William Jones e Schlegel (precursores), Bopp, Grimm e Humboldt (fundadores); (ii) os consolidadores, como Schleicher, Curtius e Fick; e (iii) os desenvolvedores, como Verner e Brugmann; tal classificação remete a uma visão linear e evolutiva dos estudos linguísticos.

\section{CONCLUSÃO}

Este texto apresentou uma revisão de algumas narrativas genealógicas que ajudaram a construir a historiografia da linguística. Optamos por enfocar séries historiográficas delineadas por quatro diferentes autorias, as quais compreendem: o estruturalismo linguístico, com base em reflexões de Saussure (CLG) e de Camara Jr.; a questão da mudança linguística com foco na dimensão estrutural e social da língua, conforme proposto por Labov; e a dimensão filosófico/sociológica da linguagem, na perspectiva de Voloshinov/Bakhtin. A partir dessas séries, tematizamos, ainda, a questão das paternidades da linguística, trazendo à tona alguns nomes tradicionalmente silenciados, como William Jones, Pãnine, Whitney e Humboldt. Relativizamos, pois, a atribuição de uma paternidade linguística única, assumindo-se a coexistência de diferentes discursos fundadores, mas ressaltando-se que, indubitavelmente, o título de Saussure como pai da linguística moderna faz jus ao seu contexto sócio-histórico e epistemológico.

Problematizamos a visão linear, sequencial, evolutiva da linguística, sinalizando para uma visão genealógica plural, em que diferentes séries históricas se entrecruzam ou se distanciam mutuamente, a exemplo das séries descritas por Saussure, Camara Jr., Labov e Bakhtin/Voloshinov, 
sendo que cada uma delas recobre uma dada temporalidade e uma dada visão de língua. Buscamos, na apresentação das perspectivas genealógicas descritas pelos autores, evidenciar aspectos e nomes por vezes invisibilizados ou pouco reconhecidos pela historiografia canônica.

Podemos, por fim, indagar: o que faz com que uma série de sobressaia e não outra? $\mathrm{O}$ que implica o apagamento de uma em detrimento de outra? Que história queremos contar sobre a linguística? Embora tais questões não sejam respondidas neste texto, acreditamos que as ideias aqui apresentadas contribuem para essa problematização mais ampla que, a nosso ver, tem relações com a configuração do saber linguístico que ajudou a definir o que conta como língua.

\section{REFERÊNCIAS}

ALLAN, Keith. (org). The Oxford Handbook of the History of Linguistics. Reino Unido: Oxford University Press, 2013.

ALPATOV, Vladimir. Soviet linguistics of the 1920s and 1930s and the scholarly heritage. In: Craig BRANDIST; Katya CHOWN (orgs.). Politics and the Theory of Language in the USSR 1917-1938: The Birth of Sociological Linguistics. Londres: Anthem Press, 2011, p. 69-88.

ALTMAN, M. Cristina. História, estórias e historiografia da linguística brasileira. Todas as Letras, v. 14, n. 1, 2012. p. 14-37.

Disponível em http://editorarevistas.mackenzie.br/index.php/tl/article/viewFile/4526/3488. Acesso em 14 de janeiro de 2018.

BENVENISTE, Émile. Problemas de Linguistica Geral II. Campinas: Pontes, 1989.

BRAGANÇA, Marcela L. L. Uma proposta de articulação teórico-metodológica entre os campos variacionista, funcionalista e dialógico para o tratamento de variação/mudança: reflexões a partir da expressão do futuro do presente. Tese (Doutorado) - Universidade Federal de Santa Catarina, Programa de Pós-Graduação em Lingüística. Florianópolis: 2017. 696 p.

BRANDIST, Craig. The rise of soviet sociolinguistics from the ashes of völkerpsychologie. Journal of the History of the Behavioral Sciences, v. 42, 3, 2006. p. 261-277. Disponível em mmw.interscience.wiley.com. Acesso em 17 de janeiro de 2018.

CAMARA, Jr. Joaquim Mattoso. História da lingüistica. 6a ed. Petrópolis/RJ: Vozes, 1975.

O Estruturalismo. Alfa, v. 11, 1967, p. 43-88. Disponível em

http://seer.fclar.unesp.br/alfa/article/view/3298/3025. Acesso em 10 de janeiro de 2017.

CAMPBELL, Lyle. Why Sir William Jones got it all wrong, or Jones' role in how to establish language families. ASJU, XL, 2006. p. 245-264.

Disponível em http://www.ehu.eus/ojs/index.php/ASJU/article/viewFile/4384/4329. Acesso em 10 de janeiro de 2018.

DAVIES, Ana Morpurgo; LEPSCHY, Giulio. History of linguistics: volume IV, nineteenth-century linguistics. Londres: Routledge, 1998.

FARACO, Carlos Alberto. A. Estudos pré-saussurianos. MUSSALIN, F; BENTES, A. C. Introdução à Linguistica 3. São Paulo: Editora Cortez, 2004. p. 27-52.

Linguística histórica: uma introdução ao estudo da história das línguas. Ed. revista e ampliada.

São Paulo: Parábola, 2005.

FOUCAULT, Michel. Microfísica do Poder. Trad. Roberto Machado. Rio de Janeiro: Graal, 1979.

HEIDERMANN, Werner; WEININGER, Markus J. (orgs.). Wilhelm von Humboldt: Linguagem, Literatura, Bildung. Florianópolis: UFSC, 2006.

JESPERSEN, Otto. Language: its nature, development and origin. London: G. Allen \& Unwin ltd., 1922. 
LABOV, William. O quadro social da mudança linguística. In: Padrões sociolinguísticos. Trad. de M. Bagno; M. M. P. Scherre; C. R. Cardoso. São Paulo: Parábola Editorial, 2008 [1972].

ROBINS, Robert H. A short history of Linguistics. Londres: 1967.

SAUSSURE, Ferdinand de. Curso de Linguística Geral. Trad. de A. Chelini; J. P. Paes; I. Blikstein. São Paulo: Editora Cultrix, 2004 [1916].

. Escritos de Linguística Geral. Org. por S. Bouquet e R. Engler; trad. de C. A. L. Salum e A. L. Franco. São Paulo: Cultrix, 2002.

SEVERO, Cristine G. O estudo da linguagem em seu contexto social: um diálogo entre Bakhtin e Labov. DELTA, v. 25, n. 2, 2009. p. 267-283.

- Por uma perspectiva social dialógica da linguagem: repensando a noção de indivíduo. Tese (Doutorado) - Universidade Federal de Santa Catarina, Programa de Pós-Graduação em Lingüística. Florianópolis: 2007. 255 p.

STURTEVANT, Edgar H. An introduction to linguistic science. New Haven: Yale University Press, 1947. VOLOSHINOV, Valentin N.; BAKHTIN, Mikhail. Marxismo e Filosofia da Linguagem. Trad. de M. Lahud; Y. F. Vieira. São Paulo: Editora Hucitec, 1988 [1929].

WEEDWOOD, Barbara. História concisa da Linguística. Trad. de M. Bagno. São Paulo: Parábola editorial, 2002.

WHITNEY, William D. A vida da linguagem. Trad. de M. A. Cruz. Petrópolis: Vozes, 2010.

Submetido em 17/11/2018

Aceito em 21/05/2019

Publicado em 06/06/2019 